This is an electronic reprint of the original article. This reprint may differ from the original in pagination and typographic detail.

Author(s): Puustinen, J.; Wu, M.; Luna, E.; Schramm, A.; Laukkanen, Pia; Laitinen, Mikko; Sajavaara, Timo; Guina, M.

Title: $\quad$ Variation of lattice constant and cluster formation in $\mathrm{GaAsBi}$

Year: $\quad 2013$

Version:

Please cite the original version:

Puustinen, J., Wu, M., Luna, E., Schramm, A., Laukkanen, P., Laitinen, M., Sajavaara, T., \& Guina, M. (2013). Variation of lattice constant and cluster formation in GaAsBi. Journal of Applied Physics, 114(24), Article 243504. https://doi.org/10.1063/1.4851036

All material supplied via JYX is protected by copyright and other intellectual property rights, and duplication or sale of all or part of any of the repository collections is not permitted, except that material may be duplicated by you for your research use or educational purposes in electronic or print form. You must obtain permission for any other use. Electronic or print copies may not be offered, whether for sale or otherwise to anyone who is not an authorised user. 


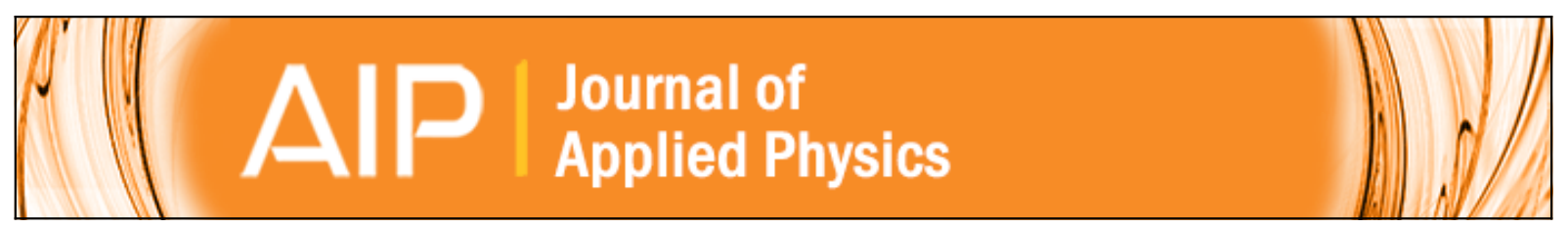

\section{Variation of lattice constant and cluster formation in GaAsBi}

J. Puustinen, M. Wu, E. Luna, A. Schramm, P. Laukkanen, M. Laitinen, T. Sajavaara, and M. Guina

Citation: Journal of Applied Physics 114, 243504 (2013); doi: 10.1063/1.4851036

View online: http://dx.doi.org/10.1063/1.4851036

View Table of Contents: http://scitation.aip.org/content/aip/journal/jap/114/24?ver=pdfcov

Published by the AIP Publishing

\section{Articles you may be interested in}

Nonstoichiometric growth and cluster formation in low temperature grown GaAsSb for terahertz-applications

J. Vac. Sci. Technol. B 24, 1556 (2006); 10.1116/1.2190677

Growth and characterization of GaAsSb metamorphic samples on an InP substrate

J. Vac. Sci. Technol. A 24, 587 (2006); 10.1116/1.2194024

Phase behavior of thin film $\mathrm{Mn} / \mathrm{GaAs}$ interfacial reactions

J. Vac. Sci. Technol. B 23, 1752 (2005); 10.1116/1.1949219

Influence of growth conditions on the lattice constant and composition of ( $\mathrm{Ga}, \mathrm{Mn}) \mathrm{As}$

Appl. Phys. Lett. 82, 4678 (2003); 10.1063/1.1586778

Structural and magnetic properties of GaMnAs layers with high Mn-content grown by migration-enhanced epitaxy on $\mathrm{GaAs}(100)$ substrates

Appl. Phys. Lett. 78, 3271 (2001); 10.1063/1.1370535

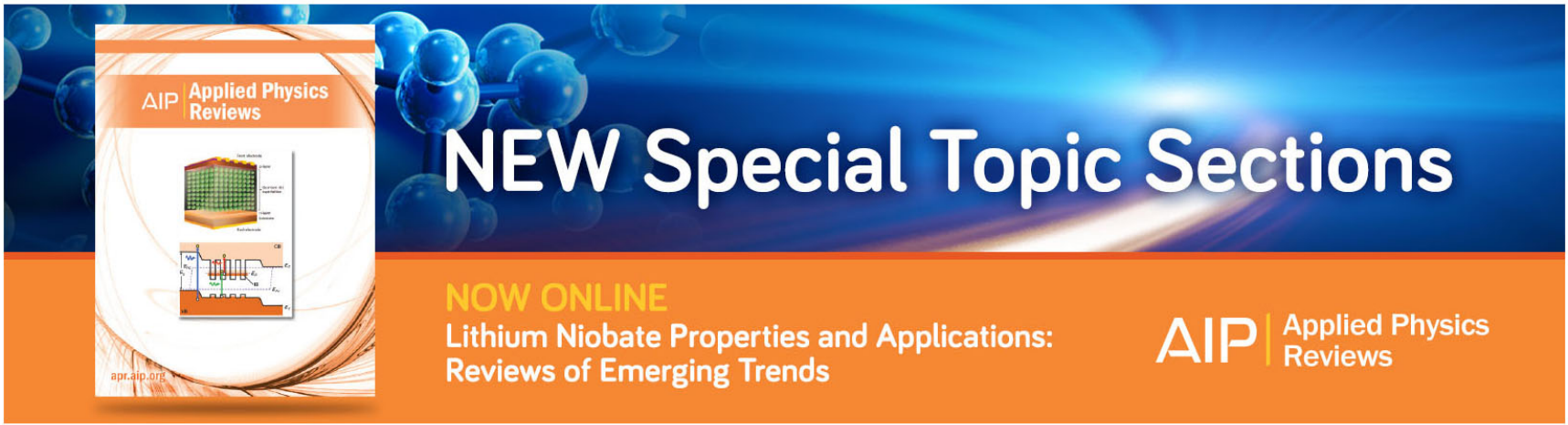




\title{
Variation of lattice constant and cluster formation in GaAsBi
}

\author{
J. Puustinen, ${ }^{1}$ M. Wu, ${ }^{2}$ E. Luna, ${ }^{2}$ A. Schramm, ${ }^{1}$ P. Laukkanen, ${ }^{3}$ M. Laitinen, ${ }^{4}$ T. Sajavaara, ${ }^{4}$ \\ and M. Guina ${ }^{1}$ \\ ${ }_{1}^{1}$ Optoelectronics Research Centre, Tampere University of Technology, P.O. Box 692, FI-33101 Tampere, \\ Finland \\ ${ }^{2}$ Paul-Drude Institut für Festkörperelektronik, Hausvogteiplatz 5-7, 10117 Berlin, Germany \\ ${ }^{3}$ Department of Physics and Astronomy, University of Turku, FI-20014 Turku, Finland \\ ${ }^{4}$ Department of Physics, University of Jyväskylä, P.O. Box 35, FI-40014 Jyväskylä, Finland
}

(Received 23 September 2013; accepted 4 December 2013; published online 23 December 2013)

\begin{abstract}
We investigate the structural properties of GaAsBi layers grown by molecular beam epitaxy on GaAs at substrate temperatures between $220-315^{\circ} \mathrm{C}$. Irrespective of the growth temperature, the structures exhibited similar Bi compositions, and good overall crystal quality as deduced from $\mathrm{X}$-Ray diffraction measurements. After thermal annealing at temperatures as low as $500{ }^{\circ} \mathrm{C}$, the GaAsBi layers grown at the lowest temperatures exhibited a significant reduction of the lattice constant. The lattice variation was significantly larger for Bi-containing samples than for $\mathrm{Bi}$-free low-temperature GaAs samples grown as a reference. Rutherford backscattering spectrometry gave no evidence of Bi diffusing out of the layer during annealing. However, dark-field and Z-contrast transmission electron microscopy analyses revealed the formation of GaAsBi clusters with a $\mathrm{Bi}$ content higher than in the surrounding matrix, as well as the presence of metallic As clusters. The apparent reduction of the lattice constant can be explained by a two-fold process: the diffusion of the excess As incorporated within $\mathrm{As}_{\mathrm{Ga}}$ antisites to As clusters, and the reduction of the Bi content in the GaAs matrix due to diffusion of $\mathrm{Bi}$ to GaAsBi clusters. Diffusion of both $\mathrm{As}$ and $\mathrm{Bi}$ are believed to be assisted by the native point defects, which are present in the low-temperature as-grown material. (c) 2013 AIP Publishing LLC. [http://dx.doi.org/10.1063/1.4851036]
\end{abstract}

\section{INTRODUCTION}

The semiconductor alloy $\mathrm{GaAs}_{1-\mathrm{x}} \mathrm{Bi}_{\mathrm{x}}$ has recently attracted attention due to its potential applications in optoelectronics. ${ }^{1-10}$ Adding small amounts of Bi to the GaAs lattice leads to a large reduction of the band gap, enabling access to important wavelengths in the infrared region. However, the successful incorporation of $\mathrm{Bi}$ within the GaAs lattice requires the use of unconventional growth procedures, such as growth temperatures near or below $400{ }^{\circ} \mathrm{C}$ and a strict control of the As flux. These temperatures are far below the optimum used for GaAs growth $\left(\sim 580^{\circ} \mathrm{C}\right)$. Recent studies suggest that temperatures as low as $200^{\circ} \mathrm{C}$ may be required in order to increase the $\mathrm{Bi}$ concentration in $\mathrm{GaAs}_{1-\mathrm{x}} \mathrm{Bi}_{\mathrm{x}}$ to values as high as $\mathrm{x}=22 \%$. $^{2}$

GaAs grown at low temperatures of $150-300{ }^{\circ} \mathrm{C}$ (LT-GaAs) has been extensively studied due to its unique material properties. In particular, LT-GaAs contains a high density of As antisites $\left(\mathrm{As}_{\mathrm{Ga}}\right)^{11}$ and $\mathrm{Ga}$ vacancies $\left(\mathrm{V}_{\mathrm{Ga}}\right){ }^{12}$ which act as fast recombination centers. ${ }^{13}$ Furthermore, when post-growth thermal annealing is applied, the As antisites transform to As clusters, ${ }^{14}$ which provide high electrical resistivity. ${ }^{15}$ These properties are very desirable in photoconductive switching applications. ${ }^{13}$ It has been recently reported that GaAsBi layers grown at low temperatures extend the wavelength range of LT-GaAs photoconductive devices, enabling the manufacture of terahertz emitters and detectors at longer wavelengths. ${ }^{3}$ However, the properties of GaAsBi grown at similar low temperatures, and its behavior under post growth treatments is still largely unknown.
Among the potential post-growth treatments, rapid thermal annealing (RTA) is commonly used to improve the quality of semiconductor materials, such as GaAsN. ${ }^{16}$ Understanding the effects of annealing is also essential when growing device structures containing layers of different materials, where some layers may need to be grown at significantly higher temperatures than others. Several works have been made concerning the effect of thermal annealing on GaAsBi, however, no clear conclusions can be made yet. The GaAsBi layers studied in those works were grown at relatively high temperatures between $345^{\circ} \mathrm{C}$ and $420^{\circ} \mathrm{C}$. ${ }^{4-9}$ Generally, X-ray diffraction (XRD) measurements of GaAsBi layers showed no significant structural deformations up to annealing temperatures of $700-800^{\circ} \mathrm{C}$, suggesting good thermal stability. $5,6,8$ Furthermore, while some studies reported improvements in the photoluminescence (PL) intensity, ${ }^{6,8}$ other works reported little or no improvement. ${ }^{4,9}$ Similarly, some authors have detected a blueshift ${ }^{4,5}$ in the PL wavelength, while one group reported a redshift of the band gap detected by photoreflectance. ${ }^{7}$ Additionally, recent experiments on annealed GaAsBi samples grown at a very low temperature of $220^{\circ} \mathrm{C}$, revealed the appearance of additional peaks in the PL spectrum at energies well below the GaAsBi bandgap, possibly arising from clusters with very high $\mathrm{Bi}$ content. ${ }^{10}$

Indeed, the growth parameters, such as the growth temperature, are expected to have a profound effect on the microstructure of the GaAsBi layers, which in turn will contribute to the behavior of the material during the annealing treatments. For example, the concentrations of both $\mathrm{As}_{\mathrm{Ga}}$ antisites and $\mathrm{Ga}$ vacancies in LT-GaAs can increase over an 
order of magnitude when the growth temperature is decreased from $300{ }^{\circ} \mathrm{C}$ to $200{ }^{\circ} \mathrm{C}$. ${ }^{11,12,17}$

In this article, we study the impact of post-growth RTA on the structural properties of GaAsBi epilayers grown by molecular beam epitaxy (MBE) at temperatures between $220^{\circ} \mathrm{C}$ and $315^{\circ} \mathrm{C}$. LT-GaAs samples grown at the same temperatures were fabricated as a reference to study the extent of $\mathrm{As}_{\mathrm{Ga}}$ antisite formation. We show that the GaAsBi material grown at the lowest temperatures exhibits major structural deformations even when annealed at temperatures as low as $500^{\circ} \mathrm{C}$. In particular, the lattice constant of the layers is found to decrease significantly after annealing towards that of the GaAs substrate. The reorganization of $\mathrm{Bi}$ atoms towards Bi-rich GaAsBi clusters along with the removal of $\mathrm{As}_{\mathrm{Ga}}$ antisites through As cluster formation are discussed in connection with this behavior.

\section{EXPERIMENTAL}

The samples were grown by solid-source MBE on semiinsulating GaAs (001) substrates. Conventional effusion cells were used for $\mathrm{Ga}$ and $\mathrm{Bi}$ and a two-zone cracker source for $\mathrm{As}_{2}$. The substrates were heated for $10 \mathrm{~min}$ at $620^{\circ} \mathrm{C}$ to remove the native oxide, after which a $110-130 \mathrm{~nm}$ thick GaAs buffer layer was grown at $580^{\circ} \mathrm{C}$. Then, the growth was interrupted and the temperature was ramped down for the growth of the target layer, which comprised either $270 \mathrm{~nm}$ of $\mathrm{GaAsBi}$ or $230 \mathrm{~nm}$ of GaAs (referred here as LT-GaAs). Samples of both materials were grown at substrate temperatures $\left(\mathrm{T}_{\mathrm{g}}\right)$ of $220^{\circ} \mathrm{C}, 270^{\circ} \mathrm{C}$, and $315^{\circ} \mathrm{C}$. During the oxide removal and the buffer growth, the temperature was monitored with an optical pyrometer. Since the pyrometer range is limited to $\mathrm{T}_{\mathrm{g}}>400^{\circ} \mathrm{C}$, the temperatures for the GaAsBi/LT-GaAs layers were monitored with a thermocouple. The thermocouple readings were calibrated by linearly extrapolating the relationship between the pyrometer values and the thermocouple values to the low temperature range.

The growth rate was $0.50 \mu \mathrm{m} / \mathrm{h}$ for the $\mathrm{GaAsBi}$ and $0.42 \mu \mathrm{m} / \mathrm{h}$ for the LT-GaAs samples, estimated by layer thickness measurements performed by XRD. The atomic As/Ga flux ratio was 1.6 for GaAsBi and 3 for LT-GaAs. The flux ratios were determined from ion gauge readings as described by Preobrazhenskii et al. ${ }^{18}$ The nominal Bi flux was the same for all samples. The as-grown samples were cut in $4 \times 4 \mathrm{~mm}$ chips, which were annealed in a RTA oven between $500{ }^{\circ} \mathrm{C}$ and $800^{\circ} \mathrm{C}$ for $60 \mathrm{~s}$ in a flowing nitrogen environment. A GaAs wafer was used as a proximity cap to protect the samples and to prevent desorption of $\mathrm{As}^{19}$ during annealing. Additionally, a series of LT-GaAs samples was grown with As/Ga flux ratios of $0.8-8.6$, a growth rate of $0.45 \mu \mathrm{m} / \mathrm{h}$ and a growth temperature of $220^{\circ} \mathrm{C}$.

The XRD spectra were measured with a triple-axis $\mathrm{X}$-ray diffractometer using the $\mathrm{Cu}-\mathrm{K} \alpha$ radiation. Rutherford backscattering spectrometry (RBS) measurements were performed with a 1.7 MV Pelletron tandem accelerator using 4.2 $\mathrm{MeV} \mathrm{He}^{2+}$ incident ions. The sample surface normal was tilted $7^{\circ}$ with respect to the incoming beam in order to avoid channeling, and the energy detector was located at an angle of $165^{\circ}$. The measured energy spectra were fitted with the SIMNRA software ${ }^{20}$ in order to determine the Bi concentration in the GaAsBi layer. (Scanning) transmission electron microscopy (S)TEM measurements were carried out on a JEOL $2100 \mathrm{~F}$ microscope equipped with a field emission gun. High-angle annular dark-field (HAADF)-STEM images were obtained with a probe semi-angle of about $14 \mathrm{mrad}$ and collected with a detector inner angle of $80 \mathrm{mrad}$, which ensures Z-contrast imaging conditions. ${ }^{21}$

\section{RESULTS AND DISCUSSION}

XRD scans from (004) planes for the as-grown GaAsBi samples and GaAsBi samples grown and annealed at various temperatures $\left(\mathrm{T}_{\mathrm{g}}, \mathrm{T}_{\mathrm{a}}\right)$ are shown in Fig. 1. In all cases, the main peak at 0 arcseconds corresponds to the GaAs substrate, while the highest intensity peak on the left side corresponds to the compressively strained GaAsBi layer. The separation of these two peaks corresponds to the amount of lattice mismatch between the GaAsBi layer and the substrate. The XRD curves of the as-grown samples were fitted with the Bede RADS software, yielding $\mathrm{GaAs}_{1-\mathrm{x}} \mathrm{Bi}_{\mathrm{x}}$ compositions of $\mathrm{x}=1.46 \%, 1.29 \%$, and $1.30 \%$ for the samples grown at $220^{\circ} \mathrm{C}, 270{ }^{\circ} \mathrm{C}$, and $315^{\circ} \mathrm{C}$, respectively. In the analysis, we assumed Vegard's law and used a literature value for the GaBi lattice constant of $6.33 \AA^{1}$. Furthermore,

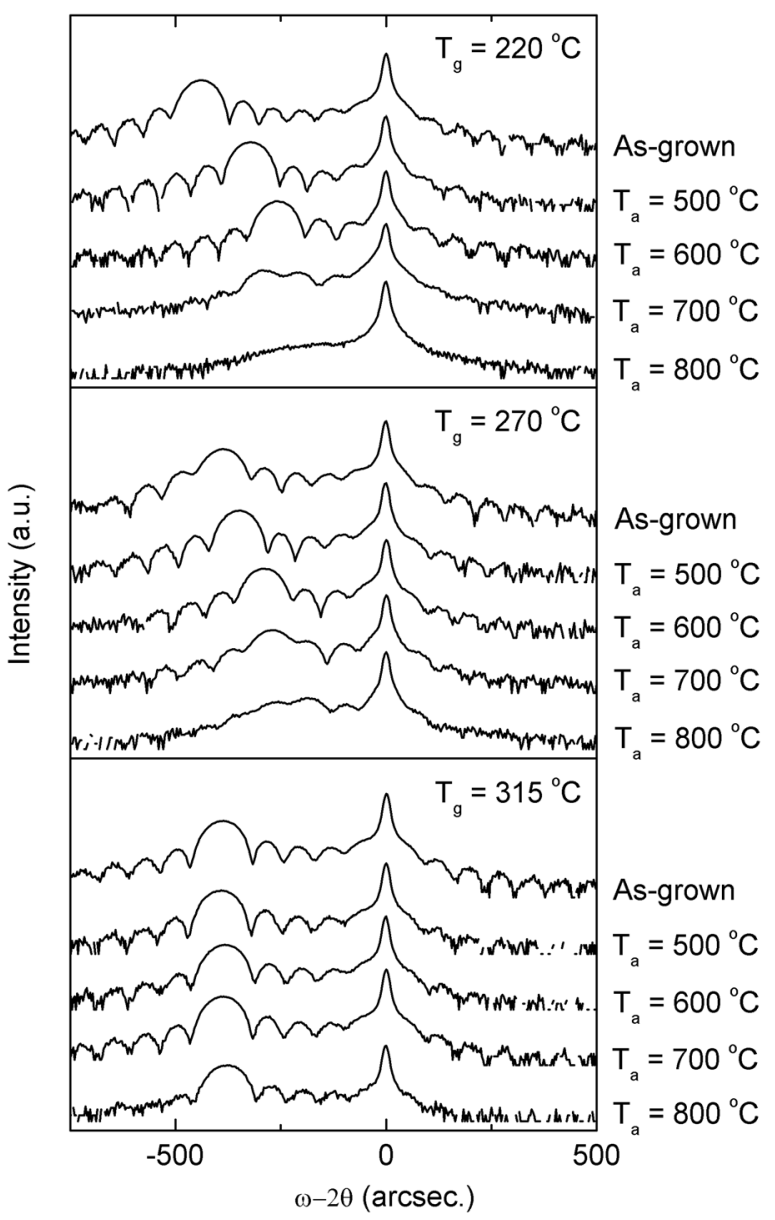

FIG. 1. XRD spectra of the GaAsBi samples for different growth $\left(\mathrm{T}_{\mathrm{g}}\right)$ and annealing temperatures $\left(\mathrm{T}_{\mathrm{a}}\right)$. 
we assumed an ideal lattice, where all Bi atoms occupy substitutional positions.

For samples grown at $220^{\circ} \mathrm{C}$ and annealed at up to $600^{\circ} \mathrm{C}$, well-defined fringes are observed around the main GaAsBi peak, which indicate an average homogeneous layer composition and good interface quality. With increasing $\mathrm{T}_{\mathrm{a}}$, the GaAsBi peak shifts towards the GaAs peak, indicating a decrease in the mismatch. Moreover, the amount of shift increases with increasing $T_{a}$. The disappearance of the fringes after annealing at $700{ }^{\circ} \mathrm{C}$ or higher temperatures suggests a significant increase of the structural disorder in the $\mathrm{GaAsBi}$ layer and/or at the GaAsBi/GaAs interface. For the sample grown at $270{ }^{\circ} \mathrm{C}$, the fringes remain clear up to an annealing temperature of $700^{\circ} \mathrm{C}$. Again, we find that the mismatch decreases after annealing; however, the effect is smaller than for the sample grown at $220^{\circ} \mathrm{C}$. Finally, for the sample grown at $315^{\circ} \mathrm{C}$, there is only a very slight decrease of the mismatch after annealing and no significant degradation of the fringes is detected even after $\mathrm{T}_{\mathrm{a}}=800^{\circ} \mathrm{C}$.

As mentioned before, GaAs grown at low temperatures contains excess As in the form of $\mathrm{As}_{\mathrm{Ga}}$. It is known that the amount of $\mathrm{As}_{\mathrm{Ga}}$ can be as high as $\sim 10^{20} \mathrm{~cm}^{-3}$, which leads to a compressive strain between the layer and the GaAs substrate, which is detectable by XRD. In order to study the extent of this effect, reference LT-GaAs samples were grown without Bi flux. First, a series of samples was grown at $220^{\circ} \mathrm{C}$ with varying As/Ga flux ratios. Fig. 2(a) displays a summary of the mismatch values in LT-GaAs samples grown using different $\mathrm{As} / \mathrm{Ga}$ ratios. The mismatch corresponds to the amount of excess As incorporated in the form of $\mathrm{As}_{\mathrm{Ga}}$

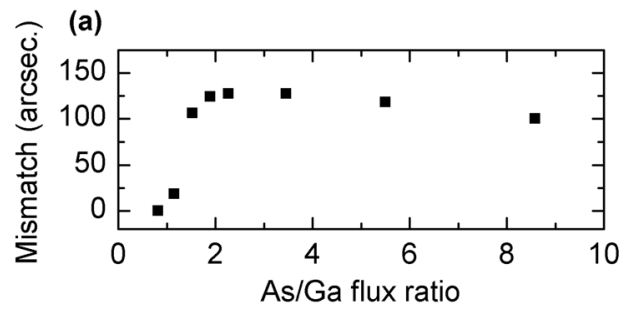

(b)

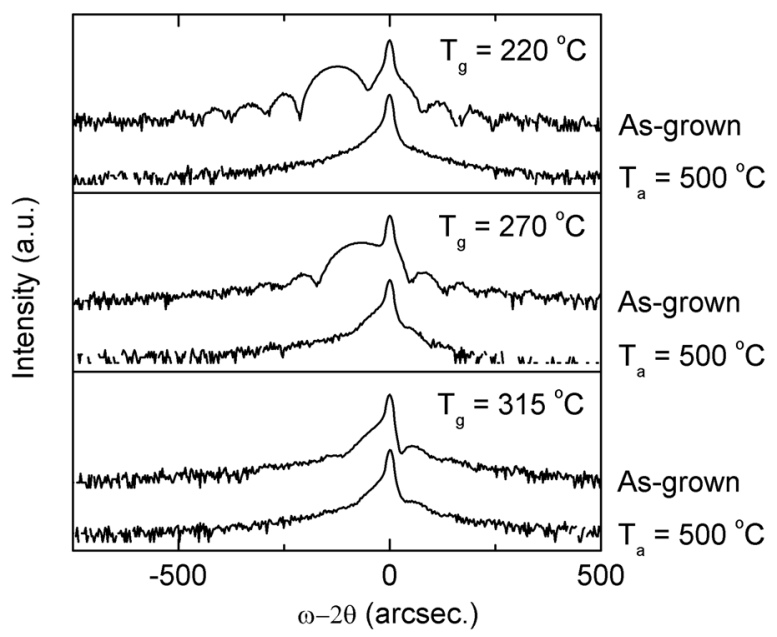

FIG. 2. (a) Mismatch in the Bi-free reference samples between the LT-GaAs layer and the $\mathrm{GaAs}$ substrate for $\mathrm{T}_{\mathrm{g}}=220^{\circ} \mathrm{C}$ using different As/Ga flux ratios. (b) XRD spectra of the LT-GaAs samples with As/Ga flux ratio of 3 for different growth and annealing temperatures. antisites. ${ }^{11}$ As observed, at this growth temperature, the amount of mismatch between the LT-GaAs and the GaAs substrate increases rapidly between flux ratios of 1 and 2, after which it saturates and slowly starts to decrease. To ensure conditions with the maximum amount of $\mathrm{As}_{\mathrm{Ga}}$, the reference LT-GaAs samples for annealing experiments were grown at an $\mathrm{As} / \mathrm{Ga}$ flux ratio of 3 .

XRD curves for as-grown and annealed LT-GaAs samples grown between $\mathrm{T}_{\mathrm{g}}=220-315^{\circ} \mathrm{C}$ are shown in Fig. $2(\mathrm{~b})$. The peak on the left side of the GaAs peak originates from the compressive LT-GaAs layer. As expected, the amount of mismatch increases with decreasing growth temperature. We observe that in all samples, the LT-GaAs peak almost completely merges into the main GaAs peak after annealing at $500{ }^{\circ} \mathrm{C}$ or higher $\mathrm{T}_{\mathrm{a}}$ (only $500{ }^{\circ} \mathrm{C}$ spectra are shown here), owing to the diffusion of the $\mathrm{As}_{\mathrm{Ga}}$ into As clusters. ${ }^{14}$ The mismatch values for the annealed GaAsBi and LT-GaAs samples are summarized in Table I. For most of the LT-GaAs samples, the epilayer peaks are so close to the substrate peak that they are no longer clearly distinguishable. In this case, the mismatch values were obtained after fitting the experimental XRD data to simulated curves.

The maximum annealing-induced shift of the mismatch can be extracted by comparing the mismatch value after annealing at the highest $T_{a}$, which still provides a clear epilayer peak with respect to the as-grown value. Shifts for the GaAsBi samples are: 182, 117, and 10 arcseconds for the layers grown at $220^{\circ} \mathrm{C}, 270^{\circ} \mathrm{C}$, and $315^{\circ} \mathrm{C}$, respectively. For the LT-GaAs layers, the shifts after the corresponding annealing treatments are 116, 73, and 20 arcseconds, respectively. We observe that for the samples grown at $220^{\circ} \mathrm{C}$ and $270^{\circ} \mathrm{C}$, the shifts for GaAsBi are considerably higher than those for LT-GaAs. This difference increases as the growth temperature is reduced. For the GaAsBi sample grown at $315^{\circ} \mathrm{C}$, we observed almost no shift, while for the LT-GaAs sample grown at this $\mathrm{T}_{\mathrm{g}}$, a minor shift of 20 arcseconds is observed. The unexpected large shifts for the GaAsBi samples suggest that there is another mechanism, in addition to the $\mathrm{As}_{\mathrm{Ga}}$ removal, contributing to the decrease in the mismatch. We should note that, although the As/Ga flux ratio used for the GaAsBi samples was clearly lower than for the LT-GaAs, several studies have shown that the surfactant effect and/or incorporation of Bi can modify the defect environment compared to samples without $\mathrm{Bi}^{22,23}$ Although we do not have direct information on the $\mathrm{As}_{\mathrm{Ga}}$ concentration in the GaAsBi samples, the fact that the mismatch of the

TABLE I. Mismatch between the GaAsBi/LT-GaAs layers and the GaAs substrate before and after annealing (arcseconds).

\begin{tabular}{lcccccc}
\hline \hline Sample & $\mathrm{T}_{\mathrm{g}}\left({ }^{\circ} \mathrm{C}\right)$ & As-grown & $500^{\circ} \mathrm{C}$ & $600^{\circ} \mathrm{C}$ & $700^{\circ} \mathrm{C}$ & $800^{\circ} \mathrm{C}$ \\
\hline GaAsBi & 220 & 438 & 322 & 256 & $\mathrm{a}$ & $\mathrm{a}$ \\
GaAsBi & 270 & 386 & 348 & 289 & 269 & $\mathrm{a}$ \\
GaAsBi & 315 & 387 & 392 & 382 & 386 & 377 \\
LT-GaAs & 220 & 128 & 11 & 12 & 9 & 8 \\
LT-GaAs & 270 & 82 & 14 & 7 & 9 & 8 \\
LT-GaAs & 315 & 20 & 10 & 0 & 0 & 0 \\
\hline \hline
\end{tabular}

${ }^{a}$ Peak position not identifiable due to deterioration of the XRD curve. 


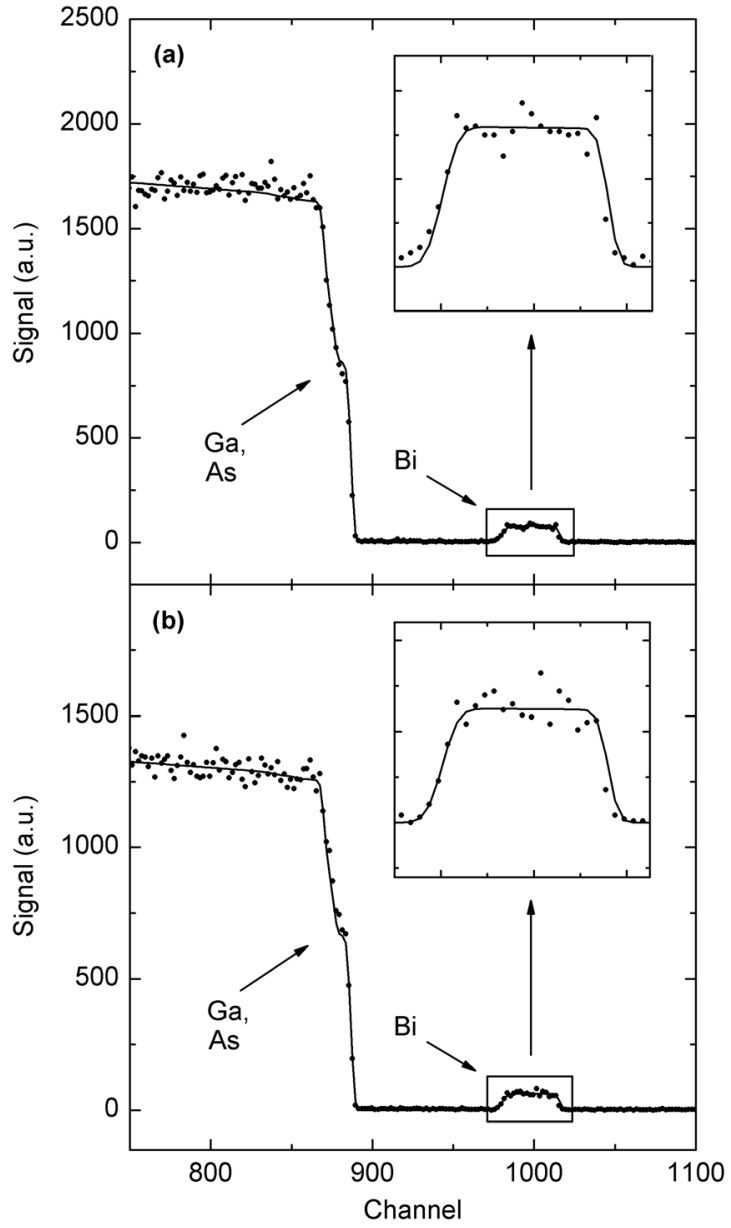

FIG. 3. RBS spectra for the GaAsBi sample grown at $220^{\circ} \mathrm{C}$ (a) as-grown and (b) annealed at $600^{\circ} \mathrm{C}$. The dots represent the experimental values and the lines represent the simulated data.

GaAsBi samples continues decreasing at higher $\mathrm{T}_{\mathrm{a}}$ (unlike the LT-GaAs samples, where annealing at $500^{\circ} \mathrm{C}$ already removes most of the mismatch) suggests that the additional shifts in GaAsBi are indeed caused by a Bi-related mechanism.

In order to investigate the possibility of $\mathrm{Bi}$ diffusing out of the epilayer, we performed RBS measurements on the GaAsBi sample exhibiting the highest shift after annealing $\left(\mathrm{T}_{\mathrm{g}}=220^{\circ} \mathrm{C}\right.$ and $\left.\mathrm{T}_{\mathrm{a}}=600^{\circ} \mathrm{C}\right)$. The experimental data can be fitted to a homogeneous $\mathrm{Bi}$ profile for both samples (see Fig. 3). Moreover, the Bi concentration estimated by RBS for both the as-grown and the annealed $\mathrm{GaAs}_{1-\mathrm{x}} \mathrm{Bi}_{\mathrm{X}}$ samples is the same, $x=1.44 \pm 0.06 \%$. Therefore, the significant reduction in the mismatch of the annealed GaAsBi layer is not due to diffusion of $\mathrm{Bi}$ out of the epilayer. We also note that RBS provides a direct indication of the atomic $\mathrm{Bi}$ concentration in the material. On the contrary, the above XRD analysis is based on information on the lattice constant and cannot distinguish contributions from $\mathrm{Bi}$ or $\mathrm{As}_{\mathrm{Ga}}$, both of which expand the GaAs lattice. Indeed, the close agreement between the $\mathrm{Bi}$ concentration values deduced from RBS $(1.44 \%)$ and XRD (1.46\%) measurements suggests that the contribution from $\mathrm{As}_{\mathrm{Ga}}$ is low and hence, reduction of $\mathrm{As}_{\mathrm{Ga}}$ can only account for a fraction of the total shift in mismatch after annealing.

We note, however, that the above XRD and RBS measurements do not reveal microscale inhomogeneities in the layers. Hence, the microstructure of the samples was further examined with (S)TEM. As observed in Fig. 4(a), displaying a representative cross-sectional chemically sensitive $\mathrm{g}=002$ dark-field TEM image, there are clear evidences of clustering in the sample grown at $220^{\circ} \mathrm{C}$ and annealed at $600{ }^{\circ} \mathrm{C}$. Contrastingly, the as-grown sample is free from clusters (images not shown here). Two size distributions of the clusters are identified: small clusters (diameter of about $5 \mathrm{~nm}$ ), and big clusters (diameter of about $12 \mathrm{~nm}$ ). Z-contrast imaging of an area close to that presented in Fig. 4(a) is shown in Fig. 4(b). In this case, the image contrast is proportional to the atomic number; therefore the brighter spots can be directly interpreted as Bi-containing clusters. The brighter spots in Fig. 4(b) (i.e., the Bi-rich clusters) appear smaller (about $8 \mathrm{~nm}$ diameter) than the big clusters revealed by the chemical sensitive imaging in Fig. 4(a). Since the contrast of the micrographs shown in Figs. 4(a) and 4(b) arises from different physical mechanisms, ${ }^{24,25}$ the above mentioned difference in the cluster size indicates the existence of a $\mathrm{Bi}$ concentration gradient peaked at the center of the cluster. This in turn suggests the nature of the GaAsBi clustering as being formed by means of spinodal decomposition, which is a general behavior of pseudo-binary III-V alloys. ${ }^{26}$ Further detailed high-resolution (HR)TEM analysis reveals Moiré interference fringes in the small clusters, which correspond to
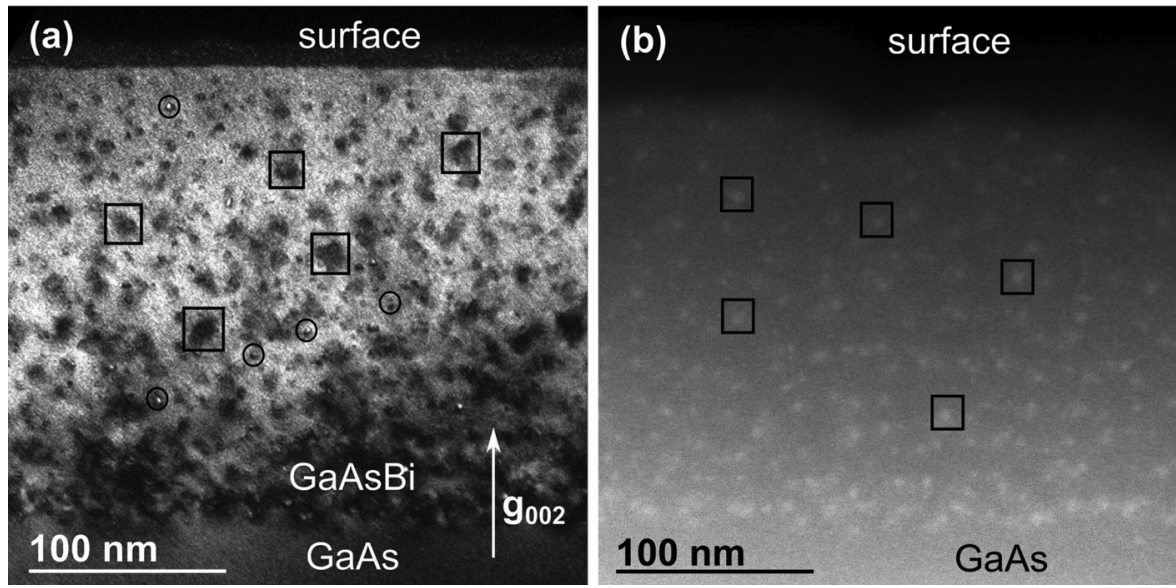

FIG. 4. Cross-section (S)TEM images of $\mathrm{GaAsBi}$ grown at $220^{\circ} \mathrm{C}$ and annealed at $600^{\circ} \mathrm{C}$. (a) The chemically sensitive $\mathrm{g}=002$ dark field image reveals two types of clusters: small ones (circles) attributed to As clusters and big ones (boxes) attributed to $\mathrm{Bi}$ rich coherently strained GaAsBi clusters. (b) Z-contrast image of an area close to that in (a). The brighter contrast reveals that most of the clusters contain the heavy Bi element. 
incoherent As clusters with rhombohedral structure, whereas HRTEM shows that the big ones are coherently strained zinc-blende GaAsBi clusters. Note that beside the clusters, no dislocations are observed in this sample. On the other hand, no evidences of clustering are detected by (S)TEM in the sample grown at $315^{\circ} \mathrm{C}$ and annealed at $600{ }^{\circ} \mathrm{C}$ (images not shown here).

We attribute the reduction in the lattice mismatch of the $\mathrm{GaAsBi}$ samples to the diffusion of $\mathrm{Bi}$ atoms to $\mathrm{GaAsBi}$ clusters with high $\mathrm{Bi}$ content, in addition to the well-known As cluster formation process from $\mathrm{As}_{\mathrm{Ga}}$ antisites. With low annealing temperatures, the GaAsBi clusters are coherent with the GaAs matrix, and the material does not exhibit large deformations as shown by the presence of well-defined fringes in the XRD spectra. Since the main changes in the microstructure occur in the GaAsBi samples grown at the lowest temperatures, we assume that the reorganization of the $\mathrm{Bi}$ atoms during annealing must be facilitated by the native defects of the as-grown samples. As mentioned before, the density of point defects in LT-GaAs (primarily $\mathrm{As}_{\mathrm{Ga}}$ antisites and $\mathrm{Ga}$ vacancies) increases rapidly with decreasing $\mathrm{T}_{\mathrm{g}}$. In particular, $\mathrm{Ga}$ vacancies are known to assist in the diffusion process of excess $\mathrm{As}^{27}$ towards As clusters and, hence, it is feasible to assume that they may also assist $\mathrm{Bi}$ diffusion in the GaAsBi samples grown at low temperatures.

\section{CONCLUSIONS}

In conclusion, the lattice constant of compressive $\mathrm{GaAsBi}$ layers grown at low temperatures $\left(220^{\circ} \mathrm{C}\right.$ and $270^{\circ} \mathrm{C}$ ) decreased significantly towards the GaAs value after post-growth annealing, while samples grown at a higher temperature $\left(315^{\circ} \mathrm{C}\right)$ did not exhibit this behavior. We attribute these findings to the reorganization of the $\mathrm{Bi}$ atoms towards GaAsBi clusters with high $\mathrm{Bi}$ content, along with the expected removal of $\mathrm{As}_{\mathrm{Ga}}$ antisites through As cluster formation. This process is enabled by the specific microstructure of the as-grown GaAsBi material, in particular, when grown at lower temperatures.

\section{ACKNOWLEDGMENTS}

We acknowledge L. Juhola for help with sample processing and D. Steffen for help with TEM specimen preparation. This work was supported by the Academy of Finland via the HIGHMAT project (Ref. No. 259111), the Academy of Finland Center of Excellence in Nuclear and Accelerator
Based Physics (Ref. Nos. 213503 and 251353), and COST Action MP0805.

${ }^{1}$ S. Tixier, M. Adamcyk, T. Tiedje, S. Francoeur, A. Mascarenhas, P. Wei, and F. Schiettekatte, Appl. Phys. Lett. 82, 2245 (2003).

${ }^{2}$ R. B. Lewis, M. Masnadi-Shirazi, and T. Tiedje, Appl. Phys. Lett. 101, 082112 (2012).

${ }^{3}$ K. Bertulis, A. Krotkus, G. Aleksejenko, V. Pačebutas, R. Adomavičius, G. Molis, and S. Marcinkevičius, Appl. Phys. Lett. 88, 201112 (2006).

${ }^{4}$ G. Feng, K. Oe, and M. Yoshimoto, Jpn. J. Appl. Phys., Part 2 46, L764 (2007).

${ }^{5}$ Y. Tominaga, Y. Kinoshita, K. Oe, and M. Yoshimoto, Appl. Phys. Lett. 93, 131915 (2008).

${ }^{6}$ I. Moussa, H. Fitouri, Z. Chine, A. Rebey, and B. E. Jani, Semicond. Sci. Technol. 23, 125034 (2008).

${ }^{7}$ Z. Chine, H. Fitouri, I. Zaied, A. Rebey, and B. E. Jani, Semicond. Sci. Technol. 25, 065009 (2010).

${ }^{8}$ A. R. Mohmad, F. Bastiman, C. J. Hunter, R. Richards, and S. J. Sweeney, Appl. Phys. Lett. 101, 012106 (2012).

${ }^{9}$ S. Mazzucato, P. Boonpeng, H. Carrère, D. Lagarde, A. Arnoult, G. Lacoste, T. Zhang, A. Balocchi, T. Amand, X. Marie, and C. Fontaine, Semicond. Sci. Technol. 28, 022001 (2013).

${ }^{10}$ R. Butkute, V. Pačebutas, B. Čechavičius, R. Adomavicius, A. Koroliov, and A. Krotkus, Phys. Status Solidi C 9, 1614 (2012).

${ }^{11}$ X. Liu, A. Prasad, J. Nishio, E. R. Weber, Z. Liliental-Weber, and W. Walukiewicz, Appl. Phys. Lett. 67, 279 (1995).

${ }^{12}$ J. Gebauer, R. Krause-Rehberg, S. Eichler, M. Luysberg, H. Sohn, and E. R. Weber, Appl. Phys. Lett. 71, 638 (1997).

${ }^{13}$ S. Gupta, M. Y. Frankel, J. A. Valdmanis, J. F. Whitaker, G. A. Mourou, F. W. Smith, and A. R. Calawa, Appl. Phys. Lett. 59, 3276 (1991).

${ }^{14}$ Z. Liliental-Weber, A. Claverie, J. Washburn, F. Smith, and R. Calawa, Appl. Phys. A 53, 141 (1991).

${ }^{15}$ A. C. Warren, J. M. Woodall, J. L. Freeouf, D. Grischkowsky, D. T. McInturff, M. R. Melloch, and N. Otsuka, Appl. Phys. Lett. 57, 1331 (1990).

${ }^{16}$ S. G. Spruytte, C. W. Coldren, J. S. Harris, W. Wampler, P. Krispin, K. Ploog, and M. C. Larson, J. Appl. Phys. 89, 4401 (2001).

${ }^{17}$ M. Luysberg, H. Sohn, A. Prasad, P. Specht, Z. Liliental-Weber, E. R. Weber, J. Gebauer, and R. Krause-Rehberg, J. Appl. Phys. 83, 561 (1998).

${ }^{18}$ V. V. Preobrazhenskii, M. A. Putyato, O. P. Pchelyakov, and B. R. Semyagin, J. Cryst. Growth 201/202, 170 (1999).

${ }^{19}$ J. Pakarinen, C. S. Peng, J. Puustinen, P. Laukkanen, V.-M. Korpijärvi, A. Tukiainen, and M. Pessa, Appl. Phys. Lett. 92, 232105 (2008).

${ }^{20}$ M. Mayer, SIMNRA User's Guide, Report No. IPP 9/113 (Max-PlanckInstitut für Plasmaphysik, Garching, Germany, 1997).

${ }^{21}$ S. J. Pennycook and D. E. Jesson, Phys. Rev. Lett. 64, 938 (1990).

${ }^{22}$ P. M. Mooney, K. P. Watkins, Z. Jiang, A. F. Basile, R. B. Lewis, V. Bahrami-Yekta, M. Masnadi-Shirazi, D. A. Beaton, and T. Tiedje, J. Appl. Phys. 113, 133708 (2013).

${ }^{23}$ A. R. Mohmad, F. Bastiman, C. J. Hunter, J. S. Ng, S. J. Sweeney, and J. P. R. David, Appl. Phys. Lett. 99, 042107 (2011).

${ }^{24}$ W. Sigle, Annu. Rev. Mater. Res. 35, 239 (2005).

${ }^{25} \mathrm{R}$. Beanland, Ultramicroscopy 102, 115 (2005).

${ }^{26}$ A. Sher, M. Schilfgaarde, A. Chen, and W. Chen, Phys. Rev. B 36, 4279 (1987).

${ }^{27}$ Z. Liliental-Weber, X. W. Lin, J. Washburn, and W. Schaff, Appl. Phys. Lett. 66, 2086 (1995). 